\title{
Facility layout planning for educational systems: An application of fuzzy GIS and AHP
}

\author{
Hossein Ebrhaimzadeh Asmin ${ }^{a^{*}}$, Fereydoun Agdam Bibabaie ${ }^{\mathrm{b}}$, Majid Davodi ${ }^{\mathrm{c}}$ and Mojtaba Omrani \\ Dourbash $^{\text {d }}$
}

\author{
${ }^{a}$ Assistant Professor, Department of Anthropology, University of Sistan and Baluchestan, Zahedan, Iran \\ ${ }^{b}$ Department of Geography and Urban Planning, University of Tabriz, Iran \\ ${ }^{c} M S c$,Department of urban planning, University of Sistan and Baluchestan, Zahedan, Iran \\ ${ }^{d}$ Department of Urban Development, University of Mohaghegh Ardabili, Ardebil, Iran

\section{H R O N I C L E}

\section{A B S T R A C T}

\section{Article history:}

Received December 28, 2013

Received in revised format April

152014

Accepted April 182014

Available online

April 232014

Keywords:

Analytical hierarch process

AHP

Fuzzy GIS

\begin{abstract}
One of the most important issues in urban planning programs is to allocate necessary spaces for educational applications. Selecting appropriate locations for training centers increases students' mental capabilities. Suitable location for the establishment of educational facilities is the first fundamental step for development of educational systems. The selection of optimal sites for educational facilities involves numerous parameters and it is essential to use multiple criteria decision making approaches to make wise decisions. This paper presents an empirical investigation on facility layout planning for educational systems in city of Birjand, Iran. Using fuzzy GIS as well as analytical hierarchy process (AHP), the study determines the most appropriate candidates for training centers.
\end{abstract}

2014 Growing Science Ltd. All rights reserved.

\section{Introduction}

Educational system in each country is one of the most important necessities for development of society. A highly educated people could make better decisions and contribute to their societies more effectively. Schools, colleges as well as universities must be located in suitable locations to better serve the residence and the locations must be based on vicinity to people's residential places and far away from hazardous facilities such as rivers, gas stations, etc. (Bin, 2009; Lotfi \& Koohsari, 2009). There are literally many studies on learning how to locate an educational facility in cities. According to Sui (1992), many analytical functions and conventional cartographic modeling method in Geographic Information Systems (GIS) are based on Boolean logic, which implicitly assumes that objects in a spatial database and their attributes are uniquely defined. The inherent limit of the classical set theory may present us for partial set membership conditions and imprecise information in GIS. Sui (1992) demonstrated the usefulness of Zadeh's fuzzy set theory in GIS modeling for urban land evaluation. Their results demonstrated that incorporating fuzzy set theory into GIS modeling could provide more details about the gradual transition of urban land value than the traditional

\footnotetext{
*Corresponding author.

E-mail addresses: h.ebrahim@lihu.usb.ac.ir (H. Ebrhaimzadeh Asmin)
} 
cartographic modeling approach. Fuzzy GIS modeling may also reduce the information loss by providing membership grade for each individual land parcel. The membership function helps identification of the extent to which a specific area is associated with a valuation class based on given criteria.

\section{The proposed study}

One of the most important issues in urban planning programs is to allocate necessary spaces for educational applications. Selecting appropriate locations for training centers increases students' mental capabilities. Suitable location for the establishment of educational facilities is the first fundamental step for development of educational systems. The selection of optimal sites for educational facilities involves numerous parameters and it is essential to use multiple criteria decision making approaches to make wise decisions. This paper presents an empirical investigation on facility layout planning for educational systems in city of Birjand, Iran. Birjand is a county in South Khorasan province, Iran and Birjand is the capital of the county. According to the 2006 census, the county's population including those portions later split off to form Khusf County was 221,756, in 60,240 families and excluding those portions, the population (as of 2006) was 196,834, in 52,986 families (See Fig. 1)

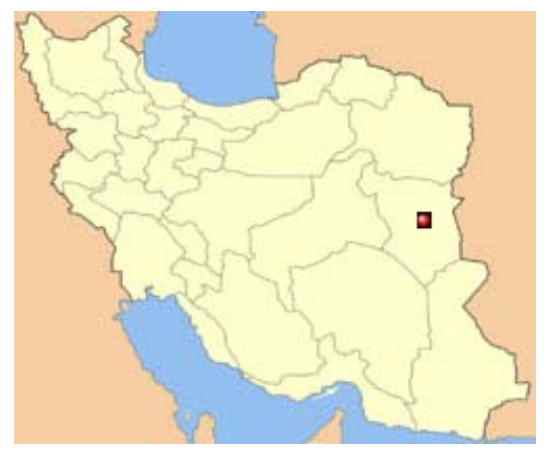

Fig. 1. The city of Brjand in east part of Iran

One of the most important issues on assigning priority is the uncertainty associated with numbers given by experts and fuzzy method helps overcome this issue (Zadeh, 1997; Morris \& Petry, 1998). Using fuzzy GIS (Sui, 1992) as well as analytical hierarchy process (AHP) (Saaty, 1990, 2003), the study determines the most appropriate candidates for training centers. Table 1 demonstrates some of the necessary criteria considered when an educational system is used.

\section{Table 1}

The summary of various criteria for educational layout facilities

\begin{tabular}{|c|c|c|}
\hline Item & Description & limitation \\
\hline 1 & Industries with high pollution & $500-1000$ \\
\hline 2 & Industries with an average pollution & $300-500$ \\
\hline 3 & Industries with low pollution & $50-100$ \\
\hline 4 & Track & 250 \\
\hline 5 & Intercity passenger terminals & 150 \\
\hline 6 & Busy commercial centers & 100 \\
\hline 7 & Highways & 150 \\
\hline 8 & Airports & 1000 \\
\hline 9 & Wastewater - waste and waste residues and gathering place & 200 \\
\hline 10 & General hospital & 150 \\
\hline 11 & Infectious Hospital & 300 \\
\hline 12 & Farm livestock, graveyards and slaughterhouses & 500 \\
\hline 13 & Cinemas & 15 \\
\hline 14 & Gas Station & 150 \\
\hline 15 & Fire Station & 250 \\
\hline 16 & Parking & 150 \\
\hline 17 & Centers of military and police & 150 \\
\hline 18 & Perennial and seasonal streams & 150 \\
\hline 19 & Fault & 300 \\
\hline
\end{tabular}




\begin{tabular}{l}
\hline $20 \quad$ Normal fault \\
In our study, we need to determine appropriate places for establishment of some primary and \\
secondary schools. The proposed study of this paper first uses AHP method to rank the one of three \\
regions of north, south and central and the results of pairwise comparison indicate that south region is \\
the most preferred one (rank $=0.486$ ) followed by central region (rank $=0.2875$ ) and north region \\
(rank $=0.2510$ ). The fuzzy GIS considers 20 different regions and prioritize them. Table 2 shows \\
details of our findings.
\end{tabular}

\section{Table 2}

The summary of fuzzy GIS for various regions

\begin{tabular}{llc}
\hline Item & Description & Rank \\
\hline 1 & Green Space & 0.046 \\
2 & Disciplinary centers & 0.005 \\
3 & Utilities and municipal equipment & 0.008 \\
4 & Religious and cultural centers & 0.023 \\
5 & Health centers & 0.011 \\
6 & Sports Centers & 0.033 \\
7 & Commercial and malls & 0.016 \\
8 & Industrial regions & 0.005 \\
9 & City terminals & 0.020 \\
10 & Repair Shops & 0.003 \\
11 & Parking & 0.033 \\
12 & Hospital for Infectious & 0.033 \\
13 & Cemeteries & 0.008 \\
14 & Watercourse & 0.002 \\
15 & Faults & 0.016 \\
16 & Slope & 0.01 \\
17 & Arterial passageway Grade 1 & 0.077 \\
18 & Arterial passageway Grade 2 & 0.011 \\
19 & Access radios & 0.128 \\
20 & Dependency & 0.305 \\
\hline
\end{tabular}

In order to rank different criteria specified in Table 2, we have used fuzzy method. For example, Fig. 2 shows details of our comparison for Green Space.

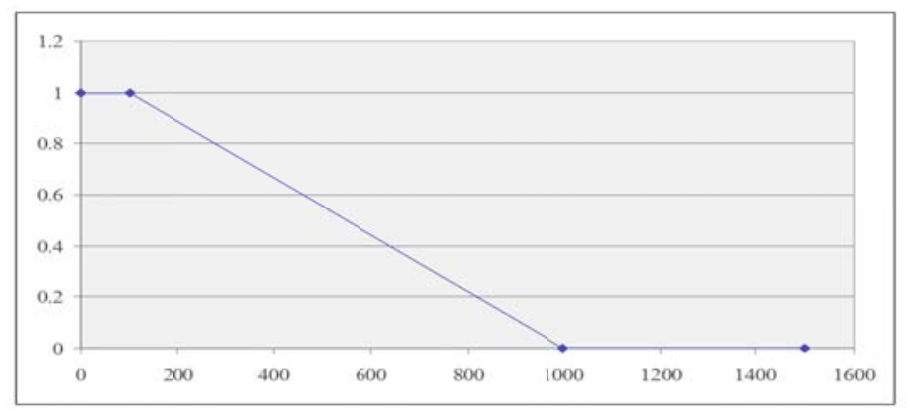

Fig. 2. The fuzzy number assigned for Green Space

There are 10 regions in south part of city Birjand and the priority of various locations for establishment of school is shown in Fig. 3. In addition, Table 3 shows details of priorities of ten regions.

\section{Table 3}

The summary of ranking 10 regions in city of Birjand for locating elementary schools

\begin{tabular}{lcccccccccc}
\hline Region & 1 & 2 & 3 & 4 & 5 & 6 & 7 & 8 & 9 & 10 \\
\hline Priority & $0.111-0.189$ & $0.189-0.229$ & $0.229-0.263$ & $0.263-0.289$ & $0.289-0.336$ & $0.336-0.378$ & $0.378-0.424$ & $0.424-0.479$ & $0.479-0.546$ & $0.546-0.647$ \\
\hline
\end{tabular}




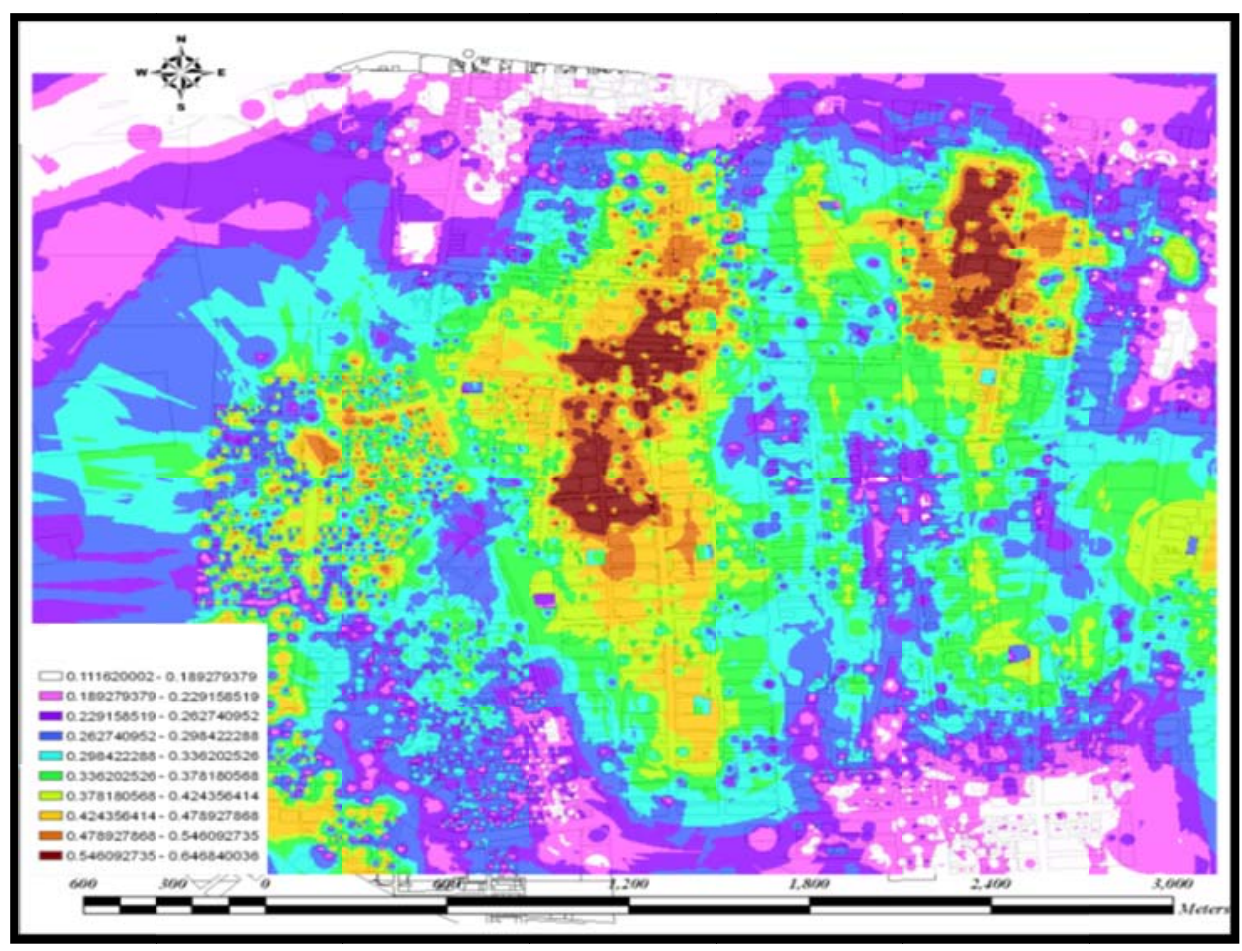

Fig. 2. The priority of ten different regions

\section{Conclusion}

In this paper, we have presented an empirical investigation to determine different factors influencing the facility location in city of Birjan, Iran. Using fuzzy GIS as well as analytical hierarchy process (AHP), the study determined the most appropriate candidates for training centers. The proposed study was capable of handling uncertainty associated with data using fuzzy numbers. Based on the results of our survey, we have determined that among three regions of north, central and south, only one region is the most appropriate place and in terms of 10 region in that region, we have prioritized them using fuzzy GIS.

\section{References}

Bin, L. (2009). The questions and countermeasures of security management and quality monitoring of schoolhouse in our country's elementary and high school. Science Mosaic, 10, 026.

Lotfi, S., \& Koohsari, M. J. (2009). Measuring objective accessibility to neighborhood facilities in the city (A case study: Zone 6 in Tehran, Iran). Cities,26(3), 133-140.

Morris, A., \& Petry, F. E. (1998, August). Design of fuzzy querying in object-oriented spatial data and geographic information systems. In Fuzzy Information Processing Society-NAFIPS, 1998 Conference of the North American (pp. 165-169). IEEE.

Saaty, T. L. (1990). An exposition of the AHP in reply to the paper "remarks on the analytic hierarchy process". Management science, 36(3), 259-268.

Saaty, T. L. (2003). Decision-making with the AHP: Why is the principal eigenvector necessary. European journal of operational research, 145(1), 85-91.

Sui, D. Z. (1992). A fuzzy GIS modeling approach for urban land evaluation. Computers, environment and urban systems, 16(2), 101-115.

Zadeh, L. A. (1997). Toward a theory of fuzzy information granulation and its centrality in human reasoning and fuzzy logic. Fuzzy sets and systems, 90(2), 111-127. 